\title{
Engaging stakeholders to achieve rehabilitation completion: a case study of the BHP Beenup Project
}

\author{
R Norrish BHP, Australia \\ B Lyon BHP, Australia \\ W Russell BHP, Australia \\ G Price $B H P$, Australia
}

\begin{abstract}
In 2018, 19 years after closure, rehabilitation of the former Beenup Titanium Minerals Project has achieved regulatory sign-off against the 21 Completion Criteria agreed with stakeholders.

The project, located in the southwest of Western Australia closed prematurely in April 1999 after only two years of operation. Stakeholder concerns for the rehabilitation of the site were high and the technical challenges complex, given the post-mine environment comprised deep dredge ponds, clay tailings disposal dams and disturbed acid sulphate soils, in an environment upstream of two rivers and a national park. The site today comprises a network of wetlands, integrated with the local drainage system and surrounded by a diverse mix of native vegetation.

The Beenup Consultative Group, formed 10 years prior to closure, played an integral part in the planning, design and oversight of rehabilitation and remains active. The site is now transitioning, with continued stakeholder input, to a monitoring and relinquishment phase requiring only minimal resources to ensure that the project tenements continue to meet statutory obligations and that design features are not compromised.

Much has been learned in progressing to this advanced stage of the closure process. Key lessons learned, particularly the value of effective stakeholder engagement throughout the planning, implementation and assessment phases of a closure project are presented in this paper.
\end{abstract}

Keywords: stakeholder engagement, community, rehabilitation, completion

\section{Introduction}

Beenup is a former titanium minerals project located in the southwest of Western Australia (Figure 1). The project was commissioned in 1997 by BHP Titanium Minerals (BHP), but operated for only two years before it was closed due to technical difficulties, primarily associated with handling the high clay content of the orebody. The original anticipated mine life was 25 years with a proposed annual throughput of $30 \mathrm{Mt}$, to produce $600,000 \mathrm{t}$ of ilmenite per annum, while mining to a depth of up to $50 \mathrm{~m}$ utilising one of the biggest dredges of its type in the world.

The project was controversial when first raised with the community in 1989 due to its size and location in an area highly valued for its natural assets. There had been no prior mining in the area and much of the community wanted to keep it that way, however, the employment potential of the project had the population split with regard to support or opposition to the mine. A 1990 survey (Nancarrow et al. 1990) identified that $46 \%$ of the community were non-supportive of the project, and $26 \%$ of the community were opposed to mining under any circumstance. Even where there was support for the project, it was conditional upon stringent environmental protection commitments being met. A lot of work was therefore required to obtain the initial project approvals and a significant component of this was a community consultation program that, while standard practice today, was very innovative at the time. With the complex nature of this project, many challenges, delays and lessons were encountered. Learnings from this project, during the 
early development and troubled operational phases, and prior to the project closure announcement in 1999, are described in (Norrish \& Nayton 1998). A key learning from the early phase was that a consultation programme must be flexible enough to change as the project plans and potential impacts change and at the same time, the people managing community relations must recognise the need to change.

The closure announcement left almost all stakeholders disappointed and/or angry including: those who welcomed the closure but felt the mine should never have been approved; those who would feel the impacts of job losses and the cessation of flow on effects to businesses and the community; and those who had invested time and energy in the consultation and regulatory processes. There was an overriding concern among most stakeholders about the actual and perceived environmental impacts of the two years of mining operations and BHP's ability to manage them after closure. At the same time BHP, being unsuccessful in arriving at technical solutions, was faced with having to close the mine in a manner considerate of environment and reputation outcomes.

This was the starting point for the closure project. In 2018, 19 years later and with significant input from many of those stakeholders (regulatory and community), the site achieved regulatory sign-off against its 21 rehabilitation completion criteria.

This paper describes the stakeholder engagement and approvals pathway that has been forged and the time taken to move from this very difficult starting point to the advanced stage of closure and acceptance that the project has now achieved.

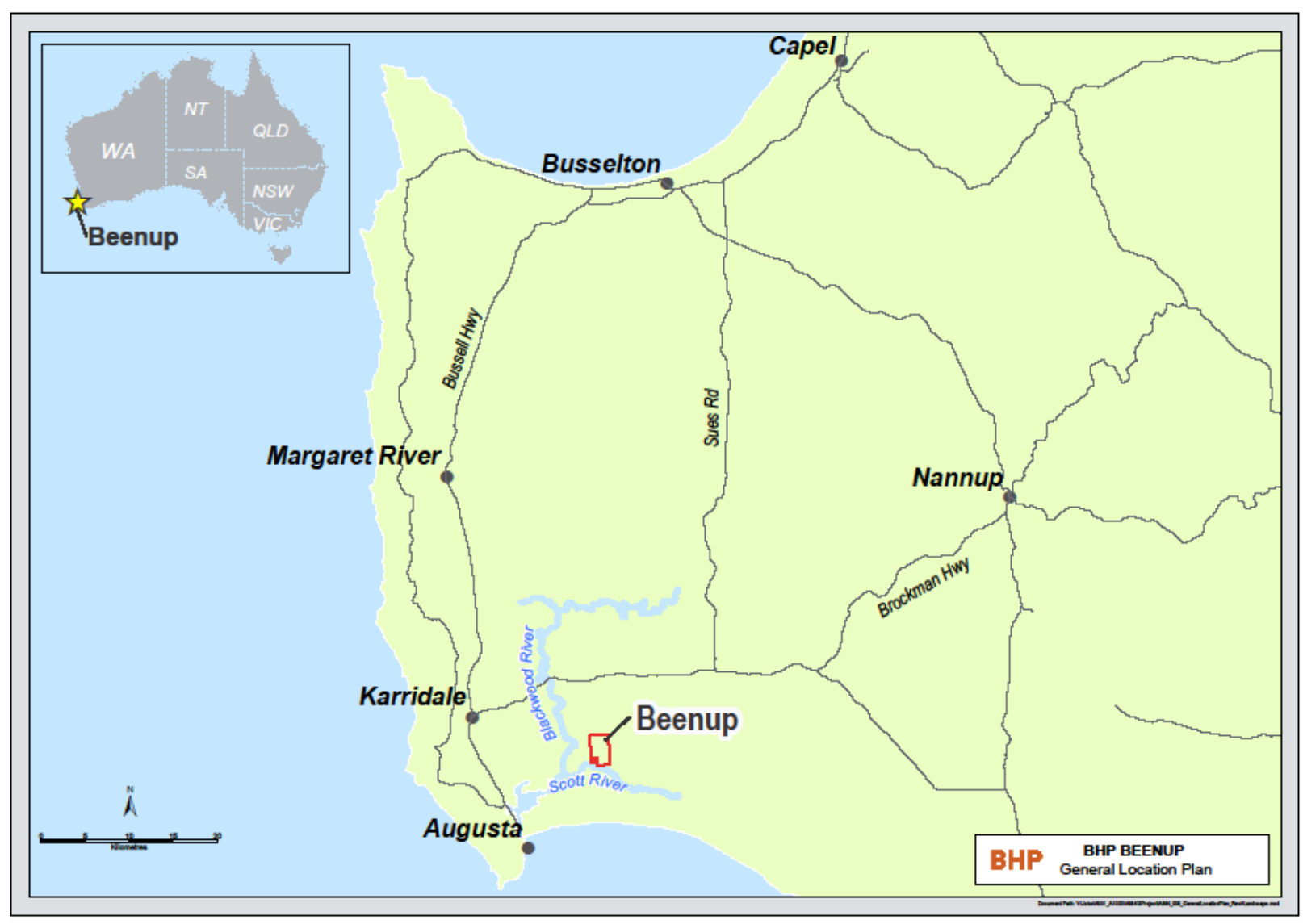

Figure 1 Location of the former BHP Titanium Minerals Beenup operation in southwestern Australia 


\section{$2 \quad$ Planning phase (1999)}

\subsection{The positives for closure planning}

Although the operation closed prematurely this did not reflect the integrity of project development and management overall. Project attributes of value to the closure process included:

- An established and active consultative group, the Beenup Consultative Group (BCG), with welldefined roles and objectives. The group was independent, chaired by a representative from the Local Shire Council and included representation from BHP.

- The substantive science undertaken to understand the settling properties of the clay. While this technology did not achieve the required clay settling rates to sustain the design throughput of the operating project, it was critical to achieving the closure outcome from both a timing and materials balance perspective.

- High quality and well-managed project baseline data and a well designed and constructed network of groundwater monitoring bores.

- A well understood and documented database of statutory requirements and stakeholder commitments.

- A committed workforce from which to select employees that would understand the new objectives and priorities for rehabilitation, provide innovative solutions to rehabilitation challenges and see the project through.

- The final land use goals had been agreed in 1989 (Lewis Environmental Consultants 1990) by a final land use work party (including government representation and the BCG) and they had been subject to a public assessment process.

All disturbance (apart from some diversion drains and monitor bores) was on freehold land owned by BHP.

\subsection{The challenges for closure planning}

An unplanned closure, so soon after commencement of operations, did however have particular challenges. These challenges included:

- How to effectively engage with stakeholders and agree on a path forward given the project history and circumstances of closure described earlier.

- The desire and expectation to commence with immediate rehabilitation of the site and therefore a short time frame for closure planning, consultation and approvals.

- The technical challenges given the post-mining environment comprised deep dredge ponds, clay tailings disposal dams and disturbed acid sulphate soils, in an environment upstream of two rivers and a national park (Figure 2).

- Human resources management associated with an unexpected closure, including the requirement to retain a smaller team of people with the ability and mindset to move rapidly from an operations mode to decommissioning and rehabilitation. 


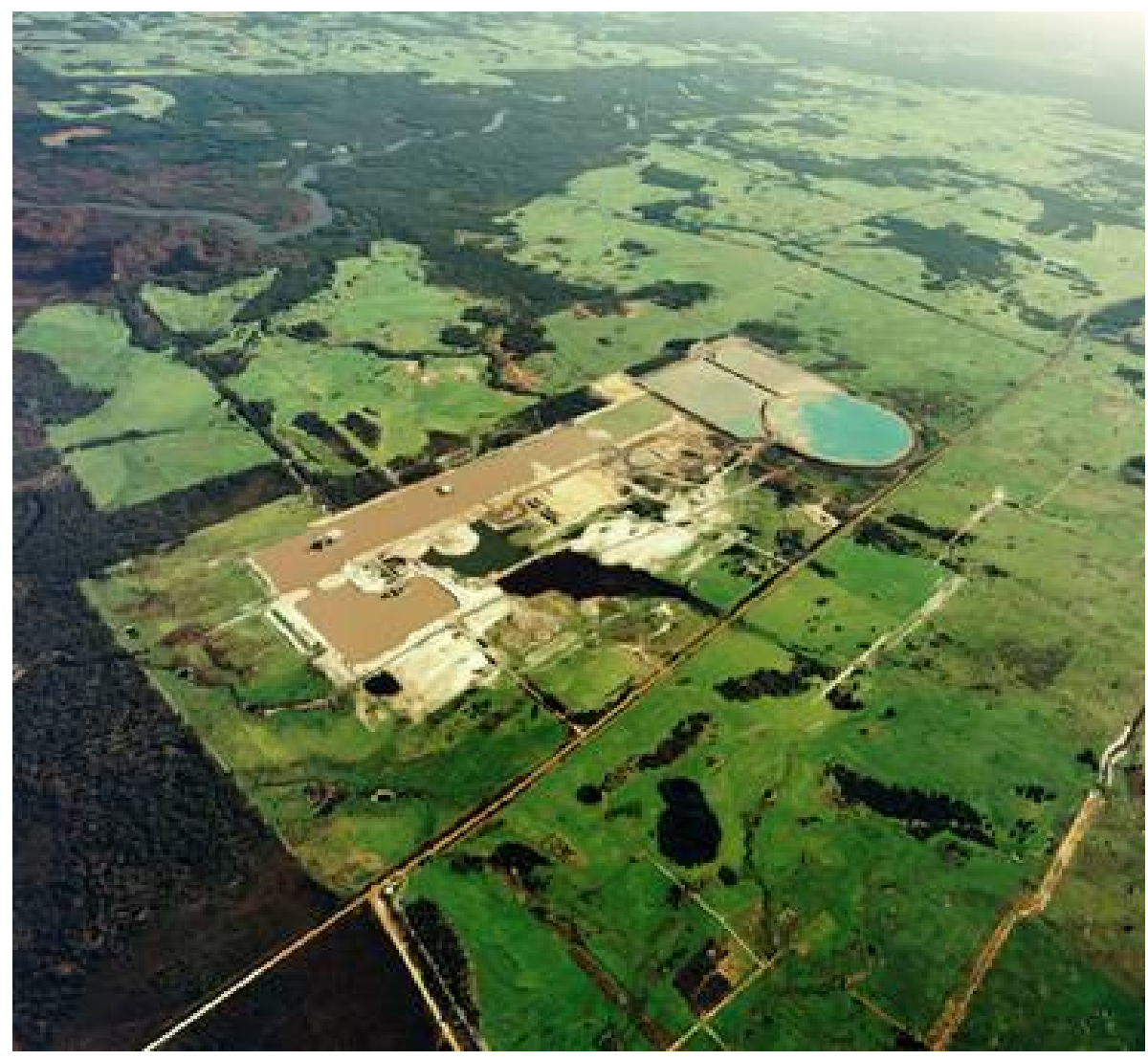

Figure 2 Beenup Titanium Minerals site at cessation of operations in 1999

\subsection{Contributors to success of closure planning}

Factors that allowed BHP to effectively utilise the established community consultation programme during the planning phase, despite the challenges at closure, are outlined below and also in (Price 2002).

\subsubsection{Selection of BHP's representation}

At the commencement of the closure process new company representatives were nominated for the BCG. It was recognised that the people who had been the public face of BHP during the operating phase could find it difficult to continue given the circumstance and reframing required for closure. Importantly however, the new representatives were still BHP employees, sufficiently senior and in relevant company roles to be able to engage effectively. Importantly, a decision was made to retain a manager as the project lead who had been with the project during the operations phase, providing an important reflection of BHP's 'ownership of the situation' and allowing for some empathy with those stakeholders who had also had to live through this challenging period.

\subsubsection{The dedication of the community}

The BCG, all unpaid volunteers, were committed to ensuring adequate community input and oversight of the closure process (they may have felt they had no choice) and were prepared to either continue in their roles or support new members. Although referred to as a single entity, the BCG are a group of individuals who bring different expertise and knowledge to the table. Involvement in such a group can sometimes be very difficult for individuals who are a minority voice on some issues.

"I've stayed on the consultative group because the mine's in my backyard. It's my backyard and I care about it." BCG Member Barbara Thomson (BHP Billiton [BHPB] 2003)

"You've got to get in, you've got to stick in there, and eventually you can see progress." BCG Member George Mardon (BHPB 2003) 
The commitment of these people cannot be overstated and the BCG was recognised with a Golden Gecko award for Environmental Excellence presented by the Department of Industry and Resources in 2003 (Department of Mines, Industry Regulation and Safety 2019).

"The exceptional long-term commitment of the Group to ensure their environmental concerns were addressed by the company...is highly commendable......setting a new standard for community consultation in the mining industry. This Award also recognises the level of commitment required to achieve these Goals" correspondence from Minister for State Development." (Minister for State Development 2003)

\subsubsection{Transparency and opportunities for input}

Re-building trust between BHP and stakeholders was always going to be a long-term task and without guarantee. Some key decisions taken in the interests of re-building trust may have sat uncomfortably with parts of BHP at the time, but on reflection have been vindicated.

One example was to provide the BCG with all the geochemical characterisation data (many thousands of assay results) collected as part of the closure planning exercise. Prior to closure, BHP had made all data from its statutory monitoring requirements available to the public, but the provision of this detailed geochemistry report meant the BCG had all the same information as BHP at that time, taking transparency to another level. This was important in demonstrating BHP's commitment to open and honest dialogue.

"We were given access to information that we'd never had access to before - facts and figures that didn't always show $\{B H P\}$ in the best light, but nevertheless they did give them to us." Peter Warrilow BCG Member (BHPB 2003)

Rehabilitation options were presented to the BCG for their input and suggestions were taken on board. BHP did not approach this exercise with a blank sheet of paper. Instead they started with the previously agreed final land use (Lewis Environmental Consultants 1990), which had assumed a full mine life and progressive rehabilitation, presented the premature closure situation, and worked with the BCG from there. Workshops were held which gave all parties a chance to discuss and understand the factors limiting rehabilitation options, together with the opportunities, and created a sense of ownership. The increase in the proportion of native vegetation and the extension of this into unmined, BHP owned land to the south of the site, to create a connection with the Scott National Park, were a direct result of community input.

\subsubsection{Involving the regulators}

The effectiveness of the continued dialogue between the BCG and BHP at the commencement of closure was helped by the involvement of the other key stakeholders: the regulators. Representatives from the then Departments of Water, Environment, Conservation and the Department of Mines and Petroleum attended early BCG meetings and workshops about closure planning.

The intention was to provide both a direct line of communication and information, and also a level of comfort to the community through sharing the 'responsibility' of ensuring that BHP was going to 'do the right thing'.

"On a frequent basis we've had key people from Government departments attend the meetings as invitees. If the members have requested anything they've always been more than forthcoming. Having that direct one-on-one contact encourages a bit more confidence and trust." Nick Dornan BCG Member (BHPB 2003)

\subsection{Closure planning phase outcomes}

After the cessation of operations in April 1999, a rehabilitation plan was submitted to the Department of Environment (BHP Titanium Minerals [BHPTM] 1999) and approved in November 1999. The rapid turnaround time for approval of the Plan, which included a public review period, reflected the effectiveness of the stakeholder engagement. 
The agreed plan was to create a system of interconnected wetlands and ponds surrounded by natural vegetation that was suitable for different waterbirds and their breeding habitats, as well as providing some connection to the adjacent Scott National Park. A key driver of the preferred plan was to maximise the return of mined material stored in above-ground impoundments and also to achieve geochemical security of pyrite $\left(\mathrm{FeS}_{2}\right)$, by ensuring it preferably remained saturated, or where unavoidably exposed to air, was sufficiently buffered with lime-sand.

The agreed Completion Goal was 'to re-integrate the mine site with the surrounding natural ecosystems, and to protect the water quality of the Scott and Blackwood river systems, which will receive drainage through the wetland system' (BHPTM 1999).

The approved rehabilitation plan stipulated only these goals and described broad methods for their achievement. The 21 Completion Criteria to measure rehabilitation success came later.

\section{Implementation phase (2000-2004)}

The implementation phase of closure involved a continued effort to ensure stakeholders could contribute to progressive decisions on details of the rehabilitation plan and were satisfied that commitments were being met.

\subsection{The challenges at the start of the implementation phase}

At the start of the implementation phase, stakeholder confidence in BHP remained low and there was a continued perception in some quarters that BHP generated data could not be trusted.

To compound this, the closure requirements presented a significant new issue for some of the local community: the requirement to source and transport the 130,000 tonnes of lime-sand necessary to effectively treat sulphur-containing materials at the site. Many of the regional lime-sand pits were located in controversial coastal locations and could not utilise established mine haulage routes. The requirement for lime-sand was not anticipated as part of the original project proposal.

Other key issues of stakeholder interest included: the requirement to treat and release approximately 5 million cubic metres of dredge pond water onto nearby farm-lands from a previously 'no-release' operation; methods to ensure long-term security of the permanent above-ground mined material storage facility; and remediation of former trial mining areas with localised acid sulphate soil drainage issues upstream of an adjacent river system.

\subsection{Contributors to success during the implementation phase}

\subsubsection{Continued transparency and opportunities for input}

The intensity of stakeholder engagement did not cease after approval of the rehabilitation plan. While the goals and final land use had been agreed, the BCG and regulators continued to be consulted on the 'how to' details of the plan that were still to be resolved.

This was achieved through regular meetings, site visits and workshops also attended by consultants and government agency representatives. Specific examples include attendance by BCG representatives at risk assessment workshops, meetings with regulators to develop surface water discharge criteria, a groundwater workshop specifically convened to facilitate stakeholder education, and direct involvement with the limesand supplier selection process. On this latter issue, there was not consensus support on the final decision, with the Leeuwin Conservation Group (LCG) strongly opposed. Despite this, the LCG remained involved in the BCG in the longer term to continue to contribute to implementation of the rehabilitation plan.

Updating the plan and the accompanying visual communication tools in response to this input maintained stakeholder alignment with the programme and consistency of messages. 


\subsubsection{Involvement of the regulators}

The regulatory environment during the implementation phase supported the approach described above of having government and community stakeholders working together and with BHP to address issues of concern. This was a significant factor in the success of both technical outcomes and efforts to build trust and confidence with the community.

The then Department of Water (DOW) responded to community concerns about data veracity and oversight of BHP by installing a surface water monitoring station downstream of the site (paid for by BHP but managed by DOW), with live data available for the public on line. This was a significant step in providing transparency, demonstrating government oversight and re-building confidence in BHP's performance around one of the community's greatest concerns, which was the protection of water quality. While BHP supports selfregulation and had always held the view (and continues to do so) that its own monitoring data was robust, it supported the gauging station as an appropriate and helpful response in this circumstance.

Other positive examples of regulator involvement contributing to both technical outcomes and stakeholder confidence at Beenup include: Kings Park and Botanic Gardens' utilisation of the site to conduct translocations and collect data on species from local threatened ironstone communities; the then Department of Conservation and Land Management (CALM) involvement in assessment of completion criteria; Department of Mines oversight of engineered structures; and DOW inclusion of the site in their regional macroinvertebrate sampling program. BHP held freehold title to some of the last remaining undisturbed ironstone vegetation on the Scott River plain that was transferred to CALM ownership as part of the closure program.

\subsubsection{Independent audit}

Further to the independent monitoring provided by the gauging station, BHP proposed, one year into the implementation phase, that the BCG oversee an independent audit of progress against the rehabilitation plan to that point. BHP would fund the audit but selection of the auditor and the process was to be planned and managed by the BCG.

The BCG unanimously saw this as an opportunity for them to gain further insight into BHP's performance and provide feedback to the community based on independent advice from suitably qualified people. The resultant report (BCG 2002) was made widely available to the community and the findings presented at a public meeting in June 2002.

One important inclusion in the audit process, at the request of the BCG, was a round of duplicate sampling of BHP's water monitoring sites to address questions from some stakeholders as to the veracity of data being provided by BHP.

While the audit provided a measure of rehabilitation progress and opportunities for continuous improvement, its real value was its contribution to building stakeholder confidence.

"When $\{B H P\}$ suggested that we do an audit, and that the BCG appoint the auditors, it was another great turning point in the whole process." George Mardon (BHPB 2003)

"It would give us a snapshot in time - just where the rehabilitation was at - by someone who knew what they were talking about." Larry Bunker former BCG Member (BHPB 2003)

\subsubsection{BHP commitment}

It was essential to effective stakeholder relations that BHP did what it said it was going to do. Fundamental to this was adequate resourcing of the rehabilitation project.

BHP fully committed to the decommissioning and rehabilitation budget forecasts, reflecting both an appreciation of its obligations to the community and the surrounding environment, but also to its own role as the project owner in this process and a need to maintain reputation and ensure required environmental outcomes were achieved. This was all undertaken at a time (i.e. 1999) when closure planning was not well 
understood (the Department of Mines and Petroleum guidelines on mine closure for instance were not published until 2011) and relied on both foresight and leadership of individuals involved at the time.

"I think a key to the success of the consultative process is the resourcing. If you don't have solid resourcing of that process, it would fail. We were lucky that [BHP] knew that." Terry Adams Former BCG Member (BHPB 2003)

\subsubsection{Quality of the product}

No amount of stakeholder engagement would result in a positive outcome without the right technical input and solutions. That is a key underlying factor behind the success realised at Beenup.

Building on BHP's mandate to do it once and do it well, the project, supported by a group of specialist consultants, undertook a process of rigorous materials characterisation, detailed planning of soil, water and engineering aspects, an ecosystem design based approach to revegetation (Meney \& Pantelic 2019), comprehensive QA/QC processes during and after project execution, comprehensive and rigorous data collection and storage, regular data review, peer review and continuous improvement.

The selection and mix of suitably qualified consultants and employees, almost all of whom have continued to provide service to the project for the near 20 years since operations ceased, underpins the results that have been achieved.

\subsection{Implementation phase outcomes}

By June 2005 the total area of rehabilitation reached 335 ha, effectively completing implementation of the rehabilitation plan. Surface water quality continued to meet the discharge criteria, dams were meeting design criteria, groundwater modelling had been completed with one year of successful comparison against actual results and 121 ha of native revegetation had advanced sufficiently to warrant installation of monitoring plots. Monitoring of the created wetlands by the Department of Environment (DOE) continued to indicate that the site was capable of supporting a diverse range of aquatic macro invertebrates.

\section{Rehabilitation completion (2005-2018) and beyond}

An important part of the Beenup story is the timeline (Figure 3).

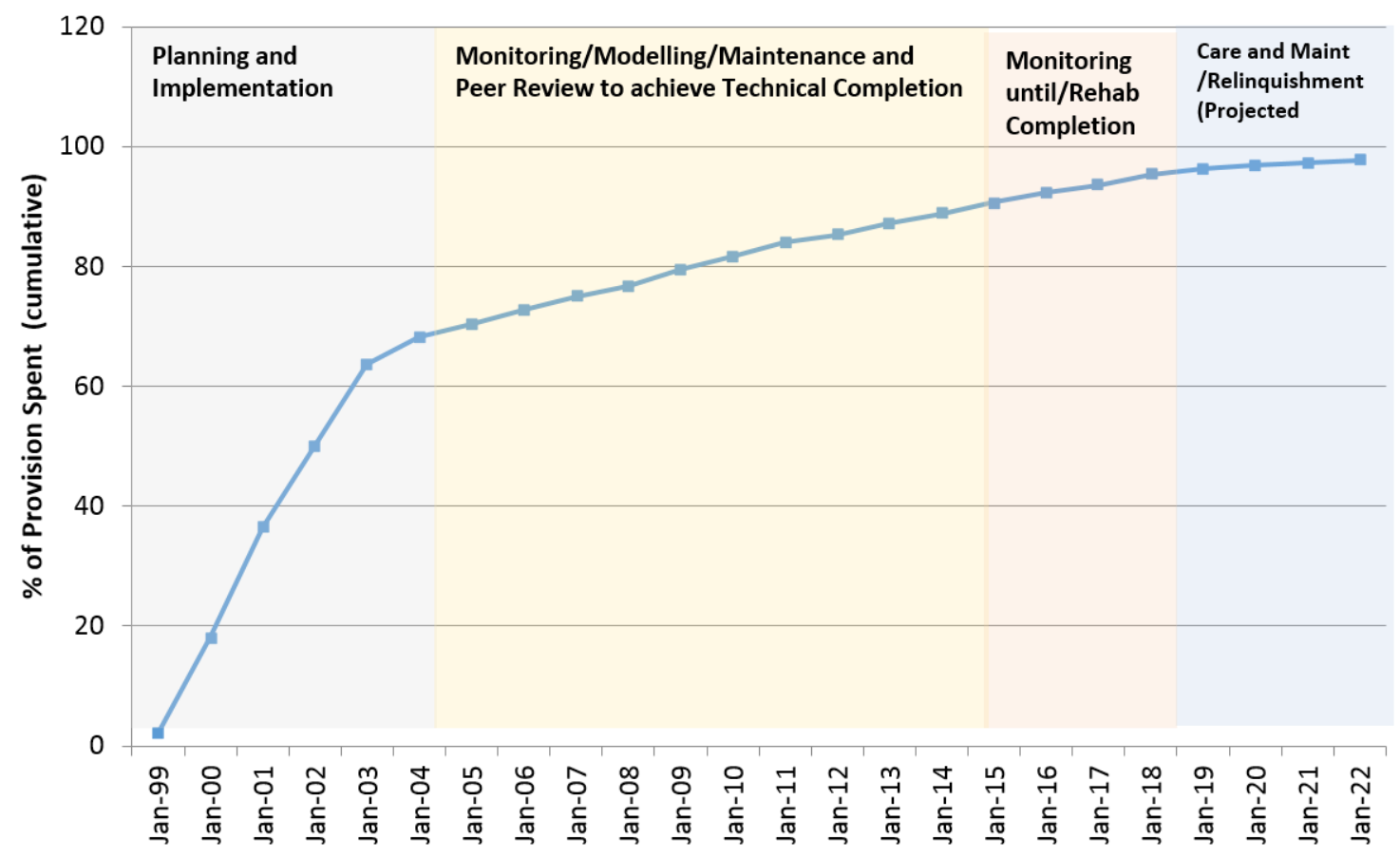

Figure 3 Percentage of provision spent over the duration of Beenup Rehabilitation Project 
The planning and implementation phases were relatively condensed and predictable time components of the closure process. The next phase, achieving technical completion, took considerably longer and was less predictable.

At the time of commencing closure (and still) there was no defined statutory pathway towards rehabilitation completion. BHP had to adopt a proactive approach driven by the aim to progressively close-out the statutory conditions and commitments that applied to the project, define and formalise 'end-points' (that would demonstrate an acceptable closure product) and demonstrate that they had been achieved. Sign-off against this achievement would require not only sufficient stakeholder confidence in the acceptability and sustainability of the site as measured by the rehabilitation completion criteria but formal recognition of this by the regulators - no small task.

\subsection{Success factors contributing to completion sign-off}

\subsubsection{Progressive completion of project conditions and commitments}

Towards the end of the project implementation phase (2004), BHP embarked on a process of progressive completion of conditions and commitments no longer applicable to the closed project (from Ministerial Statement (MS) 434 issued under Environmental Protection Act 1986) (Environmental Protection Authority 1996). By 2012, 64 of the 84 conditions had been completed. Many of the 20 remaining conditions were also redundant but required Ministerial rather than Departmental clearance.

In 2013, after BHP obtained classification of the site under the Contaminated Sites Act as 'remediated for restricted use', it was able to proceed with this Ministerial clearance. By 2015 the remaining 20 conditions from MS434 were completed/consolidated/contemporised and a new statement (MS1007) (Environmental Protection Authority 1996) was issued with five conditions, only two of which required specific actions: Compliance Reporting and Implementation of the Environmental Management Plan (EMP) (BHPB 2012). The EMP was the instrument used to formalise the rehabilitation completion criteria as described below.

\subsubsection{Establish and formalise rehabilitation completion criteria}

The conditions/commitments applicable to the project at the time of closure and even after approval of the rehabilitation plan did not include any specific rehabilitation completion criteria.

The original MS 434 required that:

- Condition 12-2: At least six months prior to decommissioning, the proponent shall prepare a decommissioning and final rehabilitation plan.

- Condition 12-3: The proponent shall implement the plan required by Condition 12-2 (Environmental Protection Authority 1996).

However, without rehabilitation completion criteria there was no formal way to measure acceptable implementation of Condition 12-3.

In parallel with the progressive sign-off process described above, rehabilitation completion criteria were developed with the involvement of the BCG and relevant State government agencies.

The process commenced in 2003 and the then DOE encouraged BHP to ensure that unrealistic targets were not being set and suggested that not all of the draft criteria should be formally audited. The final draft (BHPB 2006) proposed both completion criteria (against which rehabilitation completion would be assessed) and Value Indicators (not formally assessed but reported on as measures of rehabilitation success). The latter recognised stakeholder interest in aspects such as fauna return, even though that was not a required measure of success.

The rehabilitation completion criteria were agreed in 2007 (three years after primary rehabilitation had been executed) and on that basis BHP commenced formal reporting against them. A key subsequent step was to incorporate the completion criteria into the existing Beenup statutory regime to facilitate future formal sign- 
off. This was achieved by including them in a revised EMP, 2012 (BHPB 2012), a document (and any revisions) formally approved via MS434. The five-year delay between agreeing and formalising completion criteria allowed their 'achievability' to be tested.

When MS1007 was issued in 2015 it required that:

The proponent shall implement the proposal in accordance with the Beenup Rehabilitation Project EMP 2012... Revisions to the rehabilitation goals and completion criteria in the EMP may be approved by the CEO..." (Environmental Protection Authority 1996)

\subsubsection{Monitor to the criteria}

Having agreed the rehabilitation completion criteria in 2007, all monitoring programs were continually reviewed to ensure that they were providing the information necessary to demonstrate success. In some cases, additional monitoring or studies had to be commissioned to address particular criteria.

While not the focus of this paper, a number of lessons have been learned around the setting and application of rehabilitation completion criteria including:

- The criteria need to be achievable. This should go without saying, but is probably one of the greatest challenges in developing criteria. The rehabilitation criteria for Beenup were developed over several years, with input from stakeholders and technical experts and were formalised after project rehabilitation had been executed.

- A clear statement of 'Method of Assessment' is important. Having an approved method by which subjective targets such as 'acceptable erosion' or 'ability to withstand a fire' would be assessed facilitated reporting against achievement of these criteria, 11 years after they had been written.

- Avoid absolutes in the wording of the criteria, there needs to be room for small under-achieving areas that have failed to respond to remediation efforts, but pose no risk to overall rehabilitation success to be acceptable.

- Targets can vary across the site. For example a higher level of species richness may only be expected to be achieved for a portion of the site based onsite factors and the agreed end use.

- Allow for targets to be varied if this is justified. Beenup criteria for example refer to meeting 'baseline ranges' but did not specify these ranges. This allowed for more baseline data to be collected to ensure that the ranges were truly representative of 'baseline' without' going back to modify the approved criteria.

- Ensure that the data being collected are being correctly analysed and interpreted. At Beenup some vegetation data were reviewed at the more detailed planning unit level. This was used to guide monitoring and management work, when for completion it should have been averaged over the larger ecosystem unit level specified by the completion criteria.

- The completion criteria need to be embedded in a project statutory document.

- Even if the technical data and peer review support achievement of the rehabilitation completion criteria, more work may be required to obtain formal acknowledgement/sign-off.

\subsubsection{Regular reporting and communication}

Annual Environment Reports (AERs) from 2007 reported progress against the rehabilitation completion criteria. AER's were distributed to all members of the BCG and the relevant government agencies. Feedback was sought from the BCG at annual meetings and provided by the government agencies.

Regular feedback informed BHP about the acceptability and clarity of information being provided as well as emerging questions or expectations from stakeholders that might either need to be addressed or challenged. 
BHP also relied on the BCG as an important means of transfer of information to the broader community. This required BHP to provide frequent, clear information allowing as much time and contact as possible to facilitate adequate understanding, while being respectful of the time burden on the group of volunteers.

Site visits were a valuable part of the reporting and communication process for Beenup for both community and regulators. A shift in the regulatory environment and resourcing capacities of regulators over the last 10 years reduced both this option and the option for face to face meetings for some departments and contributed to some of the more protracted recent sign-off processes. Resolving issues by correspondence alone, particularly in relation to complex technical matters involving many experts can be inefficient, as was the case for this project. This was further compounded when dealing with the inevitable staff changes that has occurred over time.

On that note the longevity of BHP employees, consultants and some regulators involved with the project was a significant positive factor in understanding the history of any issue and progressively moving it forward with community and government. This also relies on clear and accessible documentation of that communication history.

Peer review was another process instrumental in developing confidence in the program for all stakeholders, including BHP. In addition to the 2002 audit commissioned by the BCG, peer review was carried out for the hydrological modelling, above-ground storage and levee stability, and wetland and groundwater quality.

\subsection{Outcomes at completion}

In 2018 BHP received sign-off against its 21 rehabilitation completion criteria.

What this sign-off means most significantly for the project is that environmental outcomes have been achieved. In this case, a valuable waterbird habitat has been created adjacent to a national park, consistent with local community expectations as defined by the BCG, and in accordance with the rehabilitation completion criteria (Figure 4).

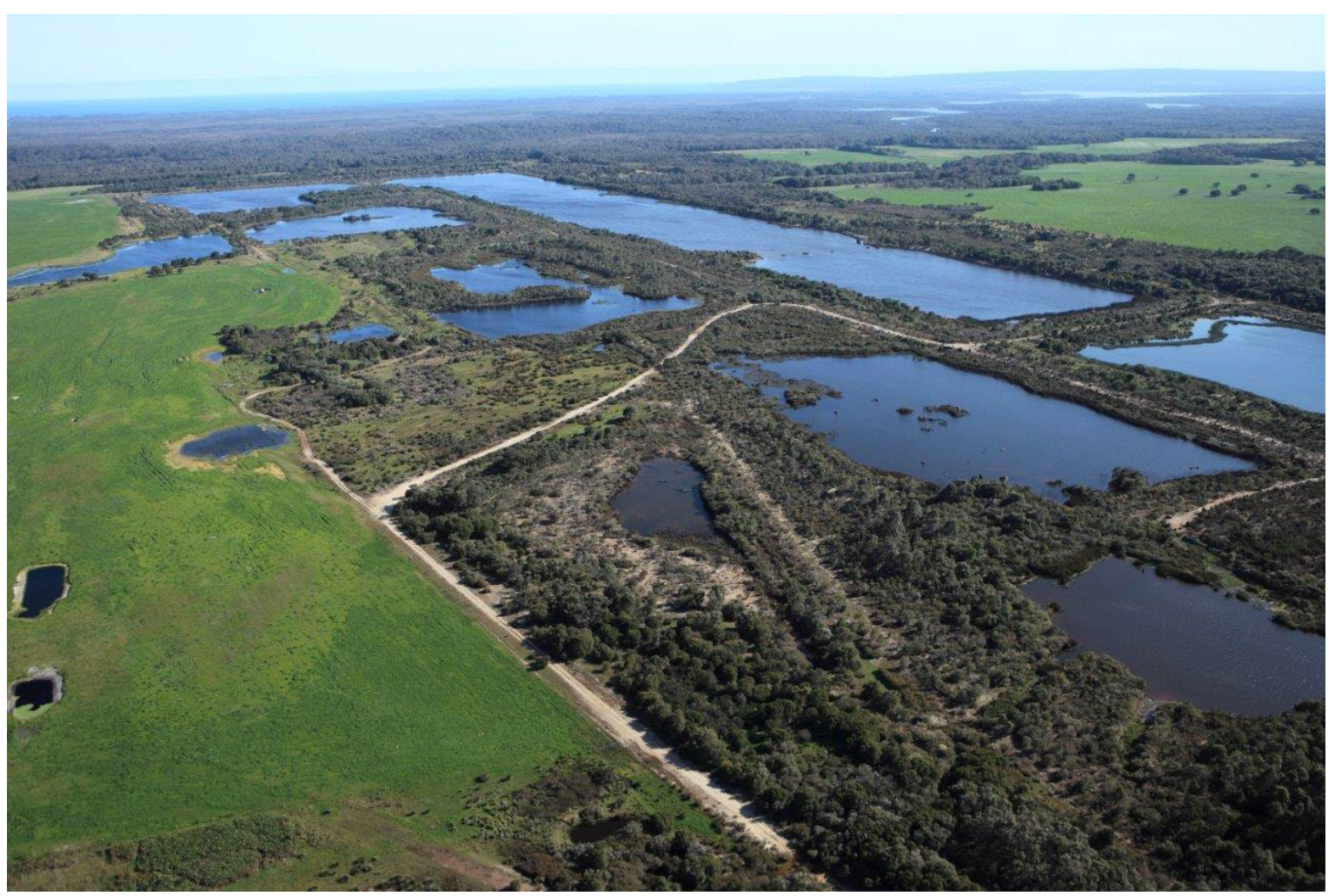

Figure 4 Beenup rehabilitation site in 2018 
Sign-off also enables the monitoring and management regime that has been necessary to demonstrate completion, to be reduced to a programme requiring only minimal resources to manage the land and residual risk factors.

While reaching this point of rehabilitation completion is significant technically and economically, final relinquishment involves two remaining statutory instruments relevant to the original operation (the Mining Leases and the State Agreement). This process has been undertaken for few, if any, mining operations in this State.

The next phase for Beenup will be to determine the completion end point of the Project and will require the same emphasis on stakeholder engagement applied to date.

"What BCG has done is important but its involvement during the next phase to ensure the site's security into the future will be its most important role" Nick Dornan BCG Member (BCG 2018)

This end point may be one or a combination of divestment, relinquishment, ongoing management or using the site for an alternative purpose (including enduring environmental and social benefits) (Heyes \& Cooper 2019).

The regulator charged with the final sign-off will need to be confident that the landforms and other features resulting from the project can continue to be managed effectively under the regulations applicable to this piece of land. Having achieved rehabilitation completion, which demonstrates sustainability, will support this process but it will also be the level of stakeholder (particularly community) confidence in the site which will underpin this process, as it has done through all closure phases at Beenup.

\section{Conclusion}

The Beenup project presents a valuable case study on how a premature mine closure can be conducted in partnership with the local community and with robust technical support to deliver an outcome that can be formally acknowledged as having met the agreed rehabilitation completion objectives.

Effective and sustained stakeholder engagement that can respond to an understanding of local issues coupled with an adequately resourced commitment to the undertakings given (and then delivering them) can take a project through to a point of sign-off against rehabilitation completion criteria.

The pathway to this point of closure can, however, take much longer than anticipated, may require addressing perceptions as well as facts and can involve a time delay between 'technical demonstration' and stakeholder acceptance.

The challenges for all parties include: navigating an uncharted regulatory pathway, accepting and responding to reasonable changes to the goal posts; challenging unreasonable changes; maintaining assessment impetus for a closed project without production/development imperatives; and overcoming the final hurdle of accepting the risk associated with sign-off.

Key learnings from the Beenup experience include:

- Companies will benefit from having employees involved who can see the project through. Continuity of BHP representation builds trustful relationships and is particularly important where you are operating in a stable resident community.

- Having a Project lead that understands the complexity of the operations, the history and the impact on Community builds trust and facilitates effective communication.

- Retaining the local consultative group was a key to the project's success.

- Enabling them to make a difference by listening and workshopping concepts during the closure planning phase, and maintaining this throughout the implementation and project assessment phases, directly benefitted the final outcome. This needs to be supported by an adaptive 
rehabilitation plan that can be updated to communicate responses to both feedback and internal improvement initiatives.

- Giving the group the resources it needed and independence to be influential by financing an independent peer review on their behalf, was a turning point in building community confidence in the rehabilitation program.

- Recognising the group along the way with the submission into the Golden Gecko awards reflected both an appreciation and the value of their contribution. The BCG (not BHP) received the award.

- The views of the group are respected by the regulators and being able to demonstrate that the community has been consulted and are comfortable, is valuable.

- Transparency builds trust, provides stakeholders with the best opportunity to contribute to reaching successful technical outcomes and creates a sense of project ownership.

- It is necessary to provide many information touch points and communicate at a sufficiently regular frequency (guided by factors such as stakeholder interest, the complexity of information to be discussed and the rate of physical progress of closure implementation) throughout the process.

- Underpinning all of this with the best science using external experts, many who have been retained throughout the course of the program, has been fundamental to the success of the rehabilitation and demonstration of rehabilitation completion. This has been particularly successful where those experts are able to communicate effectively with stakeholders.

- The selection of employees from the operations team who could transfer their mindset from operations to rehabilitation, understand the new objectives and priorities and provide innovative solutions to rehabilitation challenges, contributed greatly to the successful implementation of the rehabilitation. Engaging them closely in the project fostered a sense of pride evident in the outcomes delivered.

\section{Acknowledgement}

The contributions of many people involved in achieving successful rehabilitation of the Beenup project have been acknowledged throughout this paper.

Particular thanks are due to all past and present members of the BCG who have volunteered their time, expertise and passion for their community and environment with great integrity throughout this process.

The BHP Beenup team also sincerely thank Nick Allen (Former Vice President HSEC Assessment and Review, BHP) who set and supported the standard of what could be achieved with this closure project from its inception 20 years ago. He continues to be a much valued source of professional and personal support to the Beenup team.

\section{References}

Beenup Consulting Group 2002, Audit of Progress towards Closure and Rehabilitation of BHP Billiton's Beenup Minesite, two volumes. Beenup Consulting Group 2018, Minutes of Meeting 12 April 2018, unpublished.

BHP Billiton 2003, Department of Industry and Resources Golden Gecko Awards 2003. Beenup Consultative Group Implementation of an interactive community consultation process in the rehabilitation of the Beenup mineral sands mine in southwest Western Australia, BHP, Melbourne.

BHP Billiton 2006, Completion Criteria BHP Billiton Beenup WA, BHP, Melbourne.

BHP Billiton 2012, Beenup Rehabilitation Project Environmental Management Programme, BHP, Melbourne

BHP Titanium Minerals 1999, Rehabilitation Plan Beenup Mine Closure, BHP, Melbourne.

Department of Mines, Industry Regulation and Safety 2019, Golden Gecko Awards previous winners, Government of Western Australia, http://dmp.wa.gov.au/About-Us-Careers/Golden-Gecko-Awards-previous-23511.aspx 
Environmental Protection Authority 1996, 1007-Heavy Mineral Sands Mine, Beenup, Shire of Augusta-Margaret River, Govenrment of Western Australia, http://www.epa.wa.gov.au/1007-heavy-mineral-sands-mine-beenup-shire-augusta-\%E2\%80\%93margaret-river

Heyes, J \& Cooper, T 2019, 'Strengthening BHP's closure framework: a strategy to realise enduring value', in AB Fourie \& M Tibbett (eds), Proceedings of the 13th International Conference on Mine Closure, Australian Centre for Geomechanics, pp. 1005-1012.

Lewis Environmental Consultants 1990, Environmental Review and Management Programme, Prepared for Mineral Deposits Ltd a Member of BHP-Utah Minerals International, Melbourne.

Meney, K \& Pantelic, L 2019, 'Designing for success: applying ecological criteria to restoration at BHP Beenup, Australia', in AB Fourie \& M Tibbett (eds), Proceedings of the 13th International Conference on Mine Closure, Australian Centre for Geomechanics, pp. 185-198.

Minister for State Development 2003, 2003 Golden Gecko Awards for Environmental Excellence, Correspondence to BCG Chair, Shire of Augusta-Margaret River.

Nancarrow, BE, Syme, GJ \& Sumner, NR 1990, Community development study: Shire of Augusta-Margaret River, CSIRO Applied Social Systems and Economics Research Team, Perth.

Norrish, R \& Nayton, J 1998, 'Community Consultation: The Beenup Experience', Proceedings of the Minerals Council of Australia 23rd Annual Environmental Workshop, Melbourne.

Price, G 2002, 'Engaging stakeholders and the community', Presentation to CLR National Workshop on Best Practice Environmental Management in Mineral Sands, BHP, Melbourne. 